\title{
Systematic use of mother tongue as learning/ teaching resources in target language instruction
}

\author{
An E He
}

\author{
Correspondence: heane@ied.edu.hk \\ Department of English, The Hong \\ Kong Institute of Education, 10 Lo \\ Ping Road, Tai Po, New Territories, \\ Hong Kong
}

\begin{abstract}
This paper reports the results of a study which explored systematic use of L1 for the benefit of L2 development. Students of a comparative linguistic course in a teacher education program were asked to design a series of tasks for Chinese learners of English in local schools. Three different ways of using L1 were discerned from their design and rationale: 1) taking advantage of similarities between Chinese and English language systems; 2) taking advantage of differences between the two language systems proactively or reactively; and 3) taking advantage of learners' conceptual understanding in L1 for L2 learning. Such attempts to use L1 systematically and judiciously in $L 2$ classrooms are in line with the recent calls for a paradigm shift in bilingual/FL education (e.g., [Butzkamm and Caldwell, 2009]) and a guilt-free life in using MT in TL classrooms ([Swain, Kirkpatrick and Cummins, 2011]). Viewing L1 as potentially valuable teaching/learning resources instead of a mere source of interference opens up greater pedagogical space and hence may bear constructive implications for L2 instruction, especially in homogenous contexts where both teachers and learners share the same MT and TL.
\end{abstract}

Keywords: crosslingual transfer, using MT as learning/teaching resources

\section{Introduction}

The monolingual principle has been dominating L2/FL classrooms for decades. Advocates of this principle claim that use of mother tongue (MT) deprives learners of exposure to target language (TL). They also assert that MT has to be avoided in L2/FL instruction since it is the major impediment to TL development. Under the influence of the monolingual principle, teachers of English worldwide are urged to use English in teaching, either exclusively or as much as possible. As a result, TL becomes almost the only legitimate language in L2/FL classrooms (see [Littlewood and $\mathrm{Yu}, 2011$ ] for details). Not until recently has the monolingual view been challenged and the role of L1 as learning/teaching resources for L2/FL development acknowledged (e.g., [Butzkamm \& Caldwell, 2009Cook, 2001Cummins, 2007Kirkpatrick and Chau, 2008] and [Schecter and Cummins, 2003]). While this 'paradigm shift' [Butzkamm, 2003] has drawn increasing attention at perception level, systematic, selective and judicious use of L1 by language teachers in practice remains an issue ([Littlewood \& Yu, 2011], p. 76).

This paper reports the results of a study which attempted to address the issue by analyzing students' work produced for an undergraduate level comparative linguistics

(c) 2012 He; licensee Springer. This is an Open Access article distributed under the terms of the Creative Commons Attribution License (http://creativecommons.org/licenses/by/2.0), which permits unrestricted use, distribution, and reproduction in any medium, provided the original work is properly cited. 
course. The study is reported in four major sections below, including a brief review of the monolingual principle literature; a description of the methodology adopted for the study, and a report of the findings. The paper finishes with pedagogical implications for further work in this area.

\section{A critique of the monolingual principle}

The monolingual principle refers to exclusive use of TL as instructional language to enable learners to think in TL, with minimal interference from MT [Howatt, 1984]. For years, English-only has been a default position of ELT pedagogy. Due to a variety of reasons, for example, a concern over students' maximum exposure to English, or a perceived lack of TL competence on the part of non-native teachers, or sometimes even sheer necessity when a teacher does not share the same linguistic background with learners [Butzkamm \& Caldwell, 2009], the monolingual principle has become a taken-for-granted dogma in language instruction. At policy level (see [Littlewood \& $\mathrm{Yu}, 2011]$ ), teachers are advised by national curricula to either "ban the L1 from classroom" or "minimize" it as "the L1 is not something to be utilized in teaching but to be set aside" ([Cook, 2001], p. 404). In practice, MT-free lessons are perceived by some language teachers as "a badge of honor" and, therefore, followed closely as "a religious principle” ([Butzkamm \& Caldwell, 2009], p. 24); while for others, use of MT in TL classrooms is a "skeleton in the cupboard... a taboo subject, [and] a source of embarrassment" ([Prodromou, 2002], p. 6), often triggering a sense of guilt if they fail to comply with the doctrine.

Despite this popular belief and common practice, avoidance of L1 in L2/FL classrooms, according to [Cook (2001)], "has no straightforward theoretical rationale" (p. 410). On the contrary, empirical research in recent years has proved that MT is "the most important ally a foreign language can have" ([Butzkamm \& Caldwell, 2009], p. $24)$. Since "we only learn language once" in the sense that "every new language is confronted by an already existing MT" (ibid. p. 66), compartmentalized language pedagogy as prescribed by the monolingual principle, in effect, contradicts the interdependent nature of L1 and L2. Following the belief that the human brain has the same language faculty for L1 and L2 (perhaps L3 as well), [Cummins (1981)] proposed the interdependency hypothesis, which acknowledges the contribution of MT in TL development. This hypothesis was supported by evidence of positive crosslingual transfer in the areas of conceptual understanding (e.g., [Swain and Lapkin, 2000]), meta-cognitive skills (e.g., [Hardin, 2001]), phonological awareness and functional awareness (see [Durgunoglu, 2002] for a review), between alphabetical languages and a non-alphabetical language (Chinese) and an alphabetical language (English) ([Geva and Wang, 2001]). Such evidence led to the conviction that "learning efficiencies can be achieved if teachers explicitly draw students' attention to similarities and differences between their languages and reinforce effective learning strategies in a coordinated way across languages" ([Cummins, 2007], p. 233).

Chinese is the MT in Hong Kong. Chinese refers to a language family originally spoken by Han majority people in China. It consists of a variety of dialects such as Mandarin, Wu, Fujian, Cantonese, Xiang, Min, Gan, Hakka etc. While each dialect has its unique pronunciation system and sometimes specific lexis in spoken form, they share the same writing system known as the modern Chinese. Despite the fact that Hong 
Kong Chinese speakers use complex characters while Mandarin simplified ones, mutual intelligibility in written communication is hardly an issue since simplified characters are derived from the complex system with the same principles of word formation; and the syntactical structures used in both Cantonese and Mandarin Chinese are virtually the same in academic texts.

Chinese and English are the two major languages in Hong Kong curriculums but they are "developed through two separate monolingual instructional routes" ([Lambert, 1984], p. 13). Although approximately 91\% of the Hong Kong population speaks Cantonese Chinese as its first language, which implies a homogenous learning environment in most school settings, discrimination against Chinese in English classrooms is apparent. It is manifested in, for example, the banning of L1 in teacher talk regardless of the level and age of classroom participants, and the prescription of native-like proficiency in English as a model for local teachers of English (see [Kirkpatrick, 2007]). As [Cook argued (2001)],

"Learning a L2 is not just the adding of rooms to your house by building an extension at the back: it is the rebuilding of all internal walls. Trying to put languages in a separate compartment in the mind is doomed to failure since the compartments are connected in many ways" (p. 407).

One of the consequences of depriving students of L1 in L2 instruction is that it "reduc[es] the cognitive and metacognitive opportunities to learners" ([Macaro, 2009], p. 49). In a corpus based study of Hong Kong English classrooms, [He (2006)] observed that English lessons focus almost exclusively on pre-selected discrete grammatical structures and here-and-now or daily routine related nouns and verbs, leaving little space for development of abstract and higher order thinking skills. In a follow-up study of Chinese and English classrooms, [He (in press)] also observes that with no texts as the basis for L2 literacy development and rare use of metalinguistic items in English classrooms, cognition levels in Hong Kong secondary English classrooms are far below what learners are able to handle in their MT Chinese. Such classroom practices, which disregard the established interdependent nature of MT and TL and L2 learners' cognitive and linguistic maturity developed in MT instruction, are not only de-motivating learners, but also detrimental to the achievement of bilingual literacy in learners.

Generally speaking, there are two orientations in the critique of the monolingual principle as revealed in a survey of the relevant literature. One line of arguments focuses on practical issues such as the proportion of two languages (e.g., [Littlewood \& $\mathrm{Yu}, 2011]$ ) and different ways of code switching in TL classrooms (e.g., [Lin, 2000]); techniques of L1 and L2/FL integration in teaching (e.g., [Butzkamm \& Caldwell, 2009]); and use of MT as a means to create an affectively and linguistically favorable environment for minority learners in immersion and bilingual contexts (e.g., [Cummins 2007]). The other line of arguments is evident in the study of code switch in multilingual settings ([Creese and Blackledge, 2010]), and the relation between L1 usage and task accomplishment ([Swain \& Lapkin, 2000]). These studies have proved that L1 is not only a medium for communication, but also the most powerful mediating tool for thinking ([Vygotsky, 1987]). Following the second orientation, the current study 
explores the usefulness of MT as a cognitive/mediating tool in L2 development. It can be taken as a response to the question [Butzkamm \& Caldwell (2009)] ask, "if we don't want just to rely on the learners themselves making the connection [between MT and $\mathrm{TL}$ ] intuitively and drawing on the relevant skills, to what extent can we actively assist them?" (p. 236). This question deserves serious attention in the process of a 'pedagogical shift' from the monolingual principle to a bi(multi)lingual pedagogy.

\section{Methods}

This study aimed to establish an explicit link between MT and TL in classroom instruction. Through an analysis of students' production, the research asked 'in which ways could the Chinese language system be explored systematically so as to assist development of English in a homogeneous learning context?

\subsection{The data}

Fourteen students were enrolled in a final-year elective comparative linguistic course in a four-year undergraduate education program in Hong Kong in 2010. The students were ethnic Chinese, among whom 1/3 was Cantonese native speakers and the rest native speakers of Mandarin but picked up Cantonese to varying degrees after three and half years' stay in Hong Kong. The students were all advanced English speakers/ users with approximately 14-16 years' English instruction (10-12 years in primary and secondary schools, and four years in the tertiary education institute, where almost all English major courses are taught in English). After 40 hours' classroom instruction on similarities and differences between Chinese and English, the students were requested to complete a portfolio with three 1000-word pieces as the final assessment task. Each piece, in turn, was expected to include three major parts: a text of their own choice, illustrating a worthwhile language issue or a difficult linguistic point in the areas of phonology, lexis, syntax and discourse for Chinese learners of English in local schools; an analysis of the chosen text from a comparative perspective; and two to three tasks targeting the identified issue/point. Rationale of the design was also required for the students to demonstrate their understanding of the interrelationship of the two language systems.

Out of a total of 86 tasks in various aspects of linguistic study, the study chose to focus on the tasks in syntax for two main reasons. First, approximately half of the tasks submitted were syntactic related, probably because more time was spent on syntactical comparison in the course. Second, as mentioned before, Cantonese and Mandarin differ in pronunciation and vocabulary in spoken form, but they employ the same set of syntactical structures in written language, especially in academic literacy. Hence, syntactic tasks were considered more representative as mother tongue when the discussion concentrates on development of academic literacy for crosslingual transfer.

The findings reported below are mostly in the students' own wordings (in Italic). Changes of wordings were occasionally made so as to present the findings in a coherent manner. Due to limited space, the citations in the students' works are not included in the reference list. 


\subsection{The analytical procedures}

General principles of the grounded theory [Glaser and Strauss, 1967Charmaz, 2005Richards, 2005] were followed in the analysis. Through an iterative process between the research question and the data, the students' works were examined to locate thematic categories. The first-level codes were given to each linguistic area such as phonology, lexis, syntax and discourse. Within each of the linguistic area, the data was further divided into the second-level categories, namely, similarities or differences between Chinese and English. These broad categories were then divided again into the third-level categories where crosslingual transfer might occur (e.g., in the areas of conceptual understanding and metacognitive and metalinguistic strategies, see [Cummins, 2007], p. 233). The three-levels of the coding process eventually led to discernment of the three themes described below. These discerned themes were confirmed with the rationale provided by the students in their entries.

\section{Results}

Three chosen sample entries are presented below, each representing a theme pertaining to systematic use of Chinese in English instruction.

\subsection{Sample 1: imperatives}

The chosen text in Sample 1 was a bilingual manual of coffee/tea maker (see an excerpt below in Table 1).

Student 1 focused on a key feature in manuals/instructions, namely, imperative mood. She observed two similarities in the formation of imperative sentences in the bilingual text. "First", she reported, "an imperative sentence does not contain a subject... Second, an imperative sentence is composed of a finite verb + a NP in both languages". Step 2 in the manual was selected as an illustration:

2. (You) Addground coffee (preferably coarsely-ground) or tea.

Finite Verb $+N P$

2. (你) 加入研磨咖啡最好是粗顆粒或茶葉

Finite Verb $+N P$

With reference to corpus-based findings, Student 1 claimed that "in English, imperative mood is characterized by an omission of subject and use of the base form verbs (see Biber, Johansson, Leech, Conrad and Finegan, 1999); while in Chinese, a similar set of grammar rules is applicable (see Li, 2001)."

Apart from the similarities, Student 1 also identified some differences in the bilingual text, which was concerned with the position of modifiers in NPs and VPs. She presented the following examples in Figure 1 as evidence:

Student 1 said that "it can be observed that in Chinese, the modifier 剛好沸騰或快沸 騰的 [just a degree or so below boiling in Step 3] in the NP precedes the head noun 熱 水' [hot water] whereas in English, the modifier follows the head noun as in 'water

Table 1 Excerpt of a bilingual manual of coffee/tea maker

\begin{tabular}{|c|c|}
\hline English Version & Chinese Version \\
\hline $\begin{array}{l}\text { 1. Remove the plunger and warm the glass coffee pot by rinsing it } \\
\text { with hot water. }\end{array}$ & $\begin{array}{l}\text { 1. 拆掉活塞並用熱水預熱咖啡壶/沖 } \\
\text { 茶器 }\end{array}$ \\
\hline 2. Add ground coffee (preferably coarsely-ground) or tea. & $\begin{array}{l}\text { 2. 加入研磨咖啡 ( 最好是粗顆粒 ) } \\
\text { 或茶葉 }\end{array}$ \\
\hline 5. Hold the handle and slowly press the plunger down. & 5. 握著手把, 緩慢地按下過濾器 \\
\hline
\end{tabular}




\section{Noun Phrase}

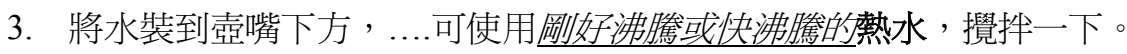
$\underline{\text { modifier }}$

Head

3. Top up with water to a level just below the spout. For the very best flavor, use

water which is just a degree or so below boiling. Stir.

Head Modifier

Verb Phrase

1. 拆掉活塞並用熱水預熱咖啡喆/沖茶器。

\section{Modifier Head}

1. Remove the plunger and warm the glass coffee pot by rinsing it with hot water.

Head Modifier

Verb Phrase

5. 握著手把, 緩慢地按下過濾器。

\section{Modifier Head}

5. Hold the handle and slowly press the plunger down.

Modifier Head

Figure 1 Excerpt of a bilingual manual of coffee/tea maker.

which is just a degree or so below boiling'. Similarly, modifiers in Chinese VPs '用熱水' [with hot water] and “緩慢地” [slowly] are positioned before the head verbs 預熱' [warm] and '按下' [press] while in English, the modifiers... either precede the head verb (e.g., 'slowly' before 'press' in Step 5), or follow the head verb (e.g., 'by rinsing it with hot water' after 'the glass coffee pot' in Step 1). These differences are due to a structural difference between the two languages. Chinese follows the principle of pre-modifier (Lin, 2001) while English allows both pre-modifier and post-modifier."

Using the bilingual coffee/tea maker manual as the text (see Table 2 below), Student 1 designed one conscious awareness task (with two sub-tasks) for secondary learners to understand the formation of imperative sentences. Below is her task instruction.

- Examine the coffee/tea maker manual in Chinese and English. Underline the action verbs (finite verbs) and circle the objects of the verbs in each version. An example is done for you below. Discuss with your partner and decide which grammatical structure(s) we use to write instructions in Chinese and English manual? (For less capable students)

(Hint: subject)

(Hint: sequence of sentence structure)

(For more capable students)

Table 2 How to Use Coffee/Tea Maker (the text is shortened due to limited space)

\begin{tabular}{ll}
\hline \multicolumn{1}{c}{ English Version } & \multicolumn{1}{c}{ Chinese Version } \\
\hline Before using for the first time & 第-次使用前 \\
.... & $\ldots$. \\
Instructions for use & 使用說明 \\
1. Remove the plunger and warm the glass coffee pot by rinsing it & 1 . 拆掉活塞並用熱水預熱咖啡壼/ \\
with hot water. & 沖茶器 \\
2. Add ground coffee (preferably coarsely-ground) or tea. & 2. 加入研磨咖啡 (最好是粗顆粒) \\
3. ... & 或茶葉 \\
& $3 . .$. \\
\hline
\end{tabular}


- Summarize how we form imperative mood in English based on your observations.

Although both similarities and differences were identified in her analysis, Student 1 chose to work on similarities in her task design. She justified her choice by saying that "the task is to activate learners' knowledge of imperative mood in L1 so that they could recall the relevant concepts and consciously think of the formation of imperative sentences in Chinese when being asked to use imperatives in English. The step-by-step task above is meant to guide learners to identify the similarities between the two languages, and enable them to take advantage of such similarities in learning English. Chinese in this case is used as a tool to help learners construct imperatives in English." To conclude, Student 1 said, "In all, instead of merely focusing on differences and L1 interferences, language teachers should be aware of the similarities between L1 and L2. Learning of the target language can be facilitated by making use of learners' linguistic knowledge in mother tongue."

\subsection{Sample 2: negative tag question}

Sample 2 was based on a personal encounter Student 2 had during a 15 week-immersion in an English speaking country one year before the course. The chosen text (see Table 3 below) was a conversation (provided by the student) between a Chinese student $L i$ and the host mum Wendy. $L i$ went out with her friends after school and came home late after the family dinner time. Wendy was trying to find out if $L i$ wanted some food.

According to Student 2, this conversation revealed a potentially difficult linguistic structure for Chinese learners of English, namely, responses to tag questions. She made two remarks on Li's responses. First, "Li had no problem in answering the Pattern A tag question, that is, 'positive declarative + negative tag'. This is evident from the third exchange in the text:

Wendy: You did eat, didn't you?

Li: No, I didn't."

Second, "Li gave a very confusing answer to the Pattern B tag question, that is, "negative declarative + positive tag'. This is evident in the second exchange:

Wendy: So, you didn't eat anything with your friends, did you?

Table 3 A conversation between $L i$ and Wendy

\begin{tabular}{ll}
\hline Wendy: & W.. Did you eat anything out there with your friends? \\
Li: & Woll, we planned to, but... \\
Wendy: & Yes, I didn't. \\
Li: & You did eat, didn't you? \\
(Wendy was a bit confused, she asked again) \\
Wendy: & No, I didn't. \\
Li: & So you didn't eat, hunh (invariant tag)? \\
Wendy: & Yes. \\
Li: & Then, there is some cold meat in the fridge.... \\
Wendy: &
\end{tabular}




\begin{tabular}{|c|c|c|}
\hline Correct English answer & Correct Chinese answer & Li's error \\
\hline $\begin{array}{l}\text { Wendy: So you didn't eat } \\
\text { anything with your } \\
\text { friends, did you? } \\
\text { Li: Nd, I didn't }\end{array}$ & $\begin{array}{c}\text { Wendy: 你还没吃过东 } \\
\text { 西呢, 是吧? } \\
\text { Li:|是, 我没吃| }\end{array}$ & $\begin{array}{l}\text { Wendy: So you didn't } \\
\text { you eat anything, } \\
\text { did you? } \\
\text { Li: Yes, I didn't. }\end{array}$ \\
\hline \begin{tabular}{l|l|l}
$X$ & $Y$
\end{tabular} & $\mid x^{\prime}$ & \\
\hline
\end{tabular}

\section{Li: Yes, I didn't.}

Student 2 attempted to explain $L i$ 's problem from a comparative perspective. She indicated the difference between Chinese and English in Figure 2below.

Student 2 said that "from the chart we can see that both the negation $\times$ and the declarative statement $Y$ in English are concerned with the fact, namely, whether Li ate anything or not. Therefore, they follow the same polarity (Yu, 2007). While in Chinese, the structure is different. The literal translation of the question and answer is 'you didn't eat anything, did you'? 'Yes, I didn't'. In this case, $X$ ' is positive and $Y$ is negative in an opposite polarity." She continued: "...the answer to the interrogative question in English refers to the fact,...the negation word 'No' in this case is a polarity adjunct in agreement with the polarity in the succeeding clause 'I didn't'. However, in Chinese, the correspondent '是' [yes]acts as a reply to the tag question, commenting on the correctness of the speaker's assumption, meaning 'yes, you are right (that I did not eat)'; while the succeeding clause '我没吃' ['I did not eat'] is the reply to the fact in the main clause of the question. It seems that Li transferred her logic in Chinese directly into an English sentence. That's where and why miscommunication occurred".

To address this problem, Student 2 decided to work on learners' awareness of the difference between the Chinese and English structure. Below are her task instructions.

- Analyze the following Chinese questions and decide if the tag questions 'yes' or 'no' address the fact in the main clause or seek (dis)agreement of the speaker's opinion in the tag question. Pay attention to the agreement (negative or positive) between the main and the tag question (the task is shortened due to limited space).

1. 她没有去过北京, 是吧?[Hasn't she been to Beijing, has she?]

- 不是, 她去过北京了 [No, she's been to Beijing]

- 是她没有去过北京 [Yes, she's not been to Beijing]

2. 马克不是住在大埔, 是不是(Marc does not live in Tai Po, does he?)

- 不, 他住在大埔 [No, he lives in Tai Po]

- 是, 他不住在大埔[Yes, he does not live in Tai Po]

3. ... 
- Examine the following sentences in English. Discuss with your partner whether the 'yes'/'no' refers to the fact in the question or shows an agreement/disagreement with the speaker.

1. Hasn't she been to Beijing?

- Yes, she has.

- No, she hasn't.

2. Marc doesn't live in Tai Po, does he?

- Yes, he does.

- No, he doesn't.

3. ...

- Summarize your observations: when the answer is 'no', is it followed by a positive or negative clause? Do the two parts (yes/no and the clause to follow) share the same polarity?

- Compare the sentences in English with those in Chinese and identify the differences.

Student 2 also designed an error correction task with the same text used for the analysis to "check students' understanding and raise their awareness". The task is not presented here due to limited space.

In the rational, Student 2 pointed out that "there are similarities (Pattern A) and differences (Pattern B) between tag questions in Chinese and English as seen from the conversation. When the logic of the sentences is identical, and the structures are similar, learning could take place easily through positive transfer of L1 patterns (e.g., Li had no problem with Pattern A tag question). But when the logic is different, which led to different syntactical structures, errors occurred. In order to help students generalize appropriate L2 rules, it is important to help students become consciously aware of the differences."

\subsection{Sample 3: existential 'there be...' and possessive 'have'}

Sample 3 focused on a typical problem of Chinese learners, namely, confusion between the existential sentence 'there be' and possessive 'have'. The problem was identified by Student 3 in a secondary one class where she did her teaching practice a year ago. The learners were asked to give suggestions to a foreign friend regarding where to go and what to do during a holiday in Hong Kong, from which three pieces (see Table 4 below) were chosen to illustrate the problem.

Student 3 noticed that "all the three learners made a common mistake in expressing the proposition of existence. They replaced the verb 'be' with 'have' in the 'there be'

Table 4 Sample writings - holiday in Hong Kong

$\frac{\text { Learner } 1}{\text { On Saturday morning, you can go to hike because there have fresh air, it helps us relax. Then you can go to the }}$
Ladies' Street for shopping because there have many shops.
$\frac{\text { Learner } 2}{1 \text { know that on Friday you will go to Ocean Park, there have many rides and it is very excited. }}$
$\frac{\text { Learner } 3}{\text { You should go to Headland Ridges. There have many rides to play, very excited. Then you should go to Disneyland. }}$
There have a lot games to play.


structure. However, if translated into Chinese word-for-word, these sentences contain no grammatical errors at all. In the example 'there have many rides', 'there' can be translated as '那里', 'have' as '有', and 'many rides' as '很多游戏项目', which is a correct Chinese sentence. This suggests the students were probably thinking in Chinese and translated the Chinese sentences word-for-word into English, assuming that what works in Chinese grammar would also work in English."

Student 3 described that 'there are two basic meanings of '有' in Chinese. When '有' indicates existence, the subject of the sentence is 'a time or location expression' while the object is 'the person or object/entity which exists at a particular location or in a particular time slot' (Yip \& Rimmington, 2004, p. 259). For example, in '桌子上有本 书', the prepositional phrase '桌子上' [on the table] is the subject, and '本书' [a book] is the object of ' $\forall$ [have]'. However, in the English sentence 'There is a book on the table', the subject is not the prepositional phrase 'on the table' as in Chinese, but the dummy pronoun 'there' (Collins \& Hollo, 2000). 'Have' cannot be used in this case since it does not realize the proposition of existence. When' $\mathbb{W}^{\prime}[$ have] indicates possession, the subject of the sentence is the possessor and the object is the object/entity or person that belongs to the possessor (Yip \& Rimmington, 2004). For instance, in '他 有- 支笔', ‘他' [he] as the possessor is the subject and '- 支笔' [a pen] is the object to be possessed. In this case, the grammatical function '有' [have] is similar to 'have' in English, which could be translated directly into "He has a pen". Since 'have' could be used to express either possession or existence in Chinese, the students may not be able to distinguish them and consequently made a mistake by using 'have' in existential sentences in English. To address this possible confusion, three tasks were designed, the first of which aimed to target learners' conceptual understanding of 'have' in Chinese.

- Distinguish the meaning of '有' in the following Chinese sentences. Put down A if you think '有' expresses Possession; or B if you think '有' expresses Existence.

1. 靠窗户有. [There is a chair near the window.] (_)

2. 我有一个哥哥,两个姐姐. [I have one elder brother and two elder sisters.] (_)

3. 唐代有个著名诗人,名叫李白. [There was a famous poet called Li Bai in the Tang Dynasty.] (_)

4. ...

The second task focused on identifying the subject of a sentence, which, according to Student 3, "is indicative of the types of $\nabla$ ' in Chinese".

- Underline the subjects (which may not necessarily be the first word in a sentence) and decide if they are expressions of time, location or a possessor. Generalize rules regarding the use of 'there be' and 'have'.

1. 那个医生有个女儿 [That doctor has a daughter].

2. 明天晚上七点有个会 [There is a meeting at 7:00 pm tomorrow].

3. 小狗有一条短尾巴 [The dog has a short tail].

4. 黑板上有一幅画 [There is a picture on the blackboard].

5. 那里有三个杯子 [There are three cups over there].

6. 这栋大厦只有三层楼 [This building has only three storeys]. 
Rule 1: (when the subject is location or time)

Rule 2: (when the subject is a possessor)

Student 3 also designed an error correction task with the texts by the learners. The task is not presented here due to limited space.

Student 3 justified her design by saying that " 22 learners understand language rules on the basis of their knowledge and conceptual understanding of L1.... When a grammatical usage is new or different from learners' L1, learners may feel confused and try to refer back to L1 structures for help. To deal with the problem, learners' conceptual understanding in L1 is essential....Task 1 and 2 are designed for students to distinguish one meaning from the other in mother tongue."

\section{Discussion}

Despite of the limitations in the students' text analysis and task design, the three samples have conveyed a very clear message, that is, MT is a valuable resource in TL instruction. Three different ways of using L1 systematically for the benefit of L2 development can be discerned from their work. They are 1) taking advantage of similarities between Chinese and English (seen from Sample 1); 2) taking advantage of differences between the two language systems (seen from Sample 2); and 3) taking advantage of learners' conceptual understanding in L1 for L2 learning (seen from Sample 2 \& 3). These three ways are mutually complementary to each other and working in an interwoven manner.

\subsection{Taking advantage of similarities between Chinese and English}

Although nobody openly denies that most languages share certain common features, similarities between languages are not always mentioned, nor made overt use of under the influence of the TL-only pedagogy. "The fact that any language can be used to convey any proposition, from theological parables to military directives, suggests that all languages are cut from the same cloth" ([Pinker, 2002], p. 37) is consistently ignored in L2 classrooms. Fears of negative transfer are simply too overwhelming for a lot of teachers to appreciate the indispensable role of L1 in L2 development. Different from such a common sentiment, Student 1 oriented her analysis and task design towards syntactical similarities between MT and TL. She asked students to observe how Chinese and English imperative sentences were formulated, and then compare the rules across the two systems. By directing their attention to the similarities between Chinese and English, Student 1 created an opportunity for learners to make a conscious link between L1 and L2. Learning in this case is scaffolded with MT as something familiar/known for learners to rely on when they try to learn something new/ unknown in L2. In fact, regardless what is promoted in curriculums, use of MT is psycholinguistically unavoidable in language learning because "If we did not keep making correspondences between foreign language items and mother tongues items, we would never learn foreign languages at all" ([Swain 1985], p. 85). At the same time, use of MT is also pedagogically sound since similar "features need not be taught from scratch. They are directly available for incorporation into the L2 system..." ([Butzkamm \& Caldwell], 2009, p. 71). However, as the language template and grammar developed 
in L1normally stays in the background, making explicit what learners have already known subconsciously in MT, as shown in the tasks by Student1, is necessary.

\subsection{Taking advantage of the difference between Chinese and English proactively and reactively}

Differences between MT and TL are most often regarded as the source of negative transfer. However, Student 2 approached the issue differently. Instead of condemning incorrect application of MT rules in the production of TL, Student 2 made an attempt to explicate the logic and conceptual understanding underpinning the utterances of the Chinese student $L i$ and her host mum Wendy. She identified some similarities and differences in the responses of tag questions in Chinese and English and she chose to focus on the differences because it was the latter that caused miscommunication between the interlocutors. Student 2's concern in this case was not on constructing correct tag questions per se, but clarifying the confusion in communication (the logic behind the responses of negative/tag interrogatives in Chinese and English). Same as in Sample 1, the observation tasks in Sample 2 were designed to raise learners' conscious awareness of a specific syntactic structure in the two languages. But different from Sample 1, its focus was on the crosslingual differences instead of similarities. Exploration of the differences in Sample 2 is not meant for predicting learners' errors in TL as some traditional contrastive analysis tends to do, but for making the differences beneficial for L2 learning. In this case, MT is not taken as something to be 'put aside' (See [Cook, 2001]), but a resource pool for learners to make active reference to in learning a potentially problematic TL structure. In addition, having been converted into an error correction task, the problematic conversation between $L i$ and Wendy was also used as a resource for remedy work. Such proactive and reactive use of crosslingual differences is worthy of attention in the discussion of multilingual pedagogy.

\subsection{Taking advantage of conceptual understanding in Chinese for TL learning}

Though it is common knowledge that L2 learners are equipped with conceptual understanding of the world as well as certain levels of linguistic and discourse knowledge developed in MT instruction, learners' prior knowledge is either consistently ignored or deliberately avoided in Hong Kong classrooms (see [Littlewood \& Yu, 2011]). Student 3 made an attempt to address this issue in her work. She started with an analysis of learners' errors but went beyond by exploring the potential causes of the errors - a misperception of 'have' structure in Chinese. In this case, learners' understanding of 'have' in Chinese was considered a key to their correct use of 'there be' existential structure in English. In fact, the difference between 'there be' and 'have' is not difficult to clarify if the two usage of 'have' in Chinese are made explicit to learners. Unfortunately, this is hardly the case under the monolingual principle. As another student working on the same problem explained, "teachers tend to solve this problem by emphasizing the surface structure of 'there-be' again and again, and by saying 'there-be should be followed by a noun phrase, and the strucutre often includes a preposition phrase etc.'. But this technique does not seem to work. In fact the key issue here is not the syntactial strucutre of there-be but students' misunderstanding of 叉'[have]in Chinese." Some simple tasks (like Task 1 and 2 in Sample 3) which clarify the conceput in MT would help solve the problem. 
It is worth mentioning that though a number of the tasks above involve use of translation, they should not be associated with the grammar translation method which takes translation as the goal of teaching. Rather, these tasks represent some explicit attempts to "trigger deeper semantic processing" of TL rules ([Macaro, 2009]) and to "build up interlinked L1 and L2 knowledge in the students' minds" ([Cook, 2001], p. 418). Also although some of the tasks cited above were designed on the basis of learners' errors, they exceeded the conventional negative view on errors; instead, errors in these tasks were explored and utilized as a resource for teaching, leading to a creation of learning conditions for positive crosslingual transfer. Together with the others, these tasks represent the three features of judicious use of MT as advocated in [Swain, Kirkpatrick \& Cummins (2011)], namely, a) build from the known; b) provide translations for difficult grammar and vocabulary; and c) use cross-linguistic comparison to scaffold English language learning (p. 7-13).

\section{Conclusion}

In the context of calls for a paradigm shift in L2/FL instruction (see [Butzkamm \& Caldwell, 2009]) and a guilt-free life in using MT in TL classrooms [Swain, Kirkpatrick and Cummins, 2011], how to use L1 systematically and judiciously in multilingual environments remains a concern. The students' work presented above, though limited in scope and less sophisticated in linguistic analysis, has revealed some attempts to make systematic use of MT for TL development. Instead of viewing L1 use as an issue of teaching technique in the classroom, the Chinese language in their work is employed as a mediating tool and a rich resource pool for possible positive crosslingual transfer.

Using L1 as learning/teaching resources provides scaffolding for learners. By making explicit reference to learners' conceptual understanding of MT, and by raising their conscious awareness of similarities and differences between Chinese and English, learners' existing schema can be activated. Also using L1 as learning/teaching resources increases learning efficiency and smoothens learning process since it enable us "to learn a new language without at the same time returning to infancy and learning to categorize the world all over again" ([Butzkamm \& Caldwell, 2009], p. 72). Taking advantage of what students have already known conceptually, strategically, and linguistically allows a "cumulative development" and "intellectual continuity" in language development, which, according to Widdowson (2003, X), is "so strikingly absent in our field" (cited in [Butzkamm \& Caldwell, 2009], p. 242).

[Butzkamm and Caldwell (2009)] point out that "monolingual lessons without the help of the mother tongue are extrinsically possible, however, monolingual learning is an intrinsic impossibility (p. 73)". In other words, "it is a waste of time," argued [Swain, Kirkpatrick \& Cummins (2011)], "to tell students not to use Cantonese when working through cognitively/emotionally complex ideas, as they will do so covertly if not allowed to do so overtly" (p. 14). When monolingual learning is proved impossible because learners' "prior knowledge is encoded in their L1", what we need to do as language teachers is "teaching for transfer" so as to take active control over the learning process through metacognitive strategies ([Cummins, 2007], p. 231, 234). The cases reported in this paper serve as foot notes to these statements. Viewing L1 as potentially valuable resources instead of a mere source of interference opens up greater 
pedagogical space and hence may bear constructive implications for L2 instruction, especially in homogenous contexts where both teachers and learners share the same MT and TL.

The tasks reported above have shown some signs of a new orientation towards use of MT in TL classrooms. The effectiveness of the tasks, however, has to be tested in situated learning environments in real classrooms with real learners. In addition, the student teachers' perception change on the relation of MT and TL is a key issue in sustainability of continued efforts to use MT systematically in practice. These are, unfortunately, beyond the scope of the current study, but will be taken up in the studies in the near future.

\section{Acknowledgements}

The author wishes to thank Professor Merrill Swain for her guidance and critiques during the preparation of this manuscript. The author also wishes to thank all the students in the 2010 Comparative Language Studies class. The study would not have been possible without their hard work and support.

\section{Competing interests}

The author declares that he has no competing interests.

Received: 20 September 2011 Accepted: 6 January 2012 Published: 6 January 2012

\section{References}

Butzkamm, W. 2003. We only learn language once. The role of the mother tongues in FL classrooms: death of a dogma. Language Learning Journal 28(1): 29-39. doi:10.1080/09571730385200181.

Butzkamm, W, and J Caldwell. 2009. The Bilingual Reform: A paradigm shift in foreign language teaching. Tübingen: Gunter Narr Verlag.

Charmaz, K. 2005. Grounded theory in the $21^{\text {st }}$ century: applications for advancing social justice studies. In The Sage Handbook of Qualitative Research,. 3 edition. ed. N.K. Denzin \& Y.S. Lincoln. . Thousand Oaks, Calif.: Sage.

Cook, VJ. 2001. Using the first language in the classroom. Canadian Modern Language Review 57(3): 402-423. doi:10.3138/ cmlr.57.3.402

Creese, A, and A Blacklege. 2010. Translanguaging in the bilingual classroom: A pedagogy for learning and teaching? The Modern Language Journal 91(1): 103-115.

Cummins, J. 1981. The role of primary language development in promoting educational success for language minority students. Schooling and Language Minority Students: A theoretical framework Los Angles: Evaluation, Dissemination and Assessment Center, California State University 3-49.

Cummins, J. 2007. Rethinking monolingual instructional strategies in multilingual classrooms. Canadian Journal of Applied Linguistics 10: 221-240.

Durgunoglu, AY. 2002. Cross-linguistic transfer in literacy development and implications for language learners. Annals of Dyslexia 52: 189-206. doi:10.1007/s11881-002-0012-y.

Geva, E, and M Wang. 2001. The role of orthography in the literacy acquisition of young L2 learners. Annual Review of Applied Linguistics 21: 182-204.

Glaser, BC, and AL Strauss. 1967. The Discovery of Grounded Theory: strategies for qualitative research. New York: Aldine.

Hardin, VB. 2001. Transfer and variation in cognitive reading strategies of Latino fourth-grade in a Late-Exit bilingual program. Bilingual Research Journal 25(4): 539-561.

He, AE. 2006. Subject matter in Hong Kong primary English Classrooms: A critical analysis of teacher talk. Critical Inquiry in Language Studies 3(2\&3): 169-188.

He, AE. Possibility of crosslingual transfer: A comparison of Chinese and English classrooms. The Modern Language Journal.

Howatt, A. 1984. History of English Language Teaching. Oxford: Oxford University Press.

Kirkpatrick, A. 2007. World Englishes: Implications for International Communication and English Language Teaching. Cambridge: Cambridge University Press.

Kirkpatrick, A, and M Chau. 2008. One Country, two systems, three languages: A proposal for combining Cantonese, Putonghua and English in Hong Kong's schools. Asian Englishes 11(2): 32-45.

Lambert, WE. 1984. An overview of issues in immersion education. Studies on Immersion Education: A collection for United States educatorsSacramento, CA: California State Department of Education.

Lin, A. 2000. Deconstructing "mixed code". In Language and Education in Postcolonial Hong Kong, ed. Li, D.C. Li, D.C.S., Lin, A. \& Tsang, W. K. 179-194. Hong Kong: Linguistic Society of Hong Kong.

Littlewood, W, and BH Yu. 2011. First language and target language in the foreign language classroom. Language Teaching 44(1): 64-77. doi:10.1017/S0261444809990310.

Macaro, E. 2009. Teacher use of codeswitching in the second language classrooms: exploring 'optimal' use. In First Language use in Second and Foreign Language Learning,ed. M. Turnbull and J. Dailey-O'Cain. . Bristol: Multilingual Matters.

Pinker, S. 2002. The Blank Slate. The Modern Denial of Human NatureNew York: Penguin.

Prodromou, L. 2002. The role of the mother tongue in the classroom. IATEFL 6-8, Issues, April-May.

Richards, L. 2005. Handling Qualitative Data: a practical guide. London: Sage.

Multilingual Education in Practice. ed. Schecter S, Cummins J. . Portsmouth, NH: Heinemann.

Swain, M. 1985. A critical look at the communicative approach (2). ELT Journal 39(2): 76-87. doi:10.1093/elt/39.2.76. 
Swain, M, and S Lapkin. 2000. Task-based second language learning: The uses of the first language. Language Teaching Research 4(3): 252-274.

Swain, M, A Kirkpatrick, and I Cummins. 2011. How to Have a Guilt-free Life Using Cantonese in the English Class: A Handbook for the English Language Teacher in Hong Kong. Hong Kong: Research Center into Language Acquisition and Education in Multilingual Societies, Hong Kong Institute of Education.

Vygotsky, LS, RW Rieber, and AS Carton. 1987. The Collected Works of L.S. Vygotsky. New York: Plenum Press.

doi:10.1186/2191-5059-2-1

Cite this article as: He: Systematic use of mother tongue as learning/teaching resources in target language instruction. Multilingual Education 2012 2:1.

Submit your manuscript to a SpringerOpen ${ }^{\circ}$ journal and benefit from:

- Convenient online submission

- Rigorous peer review

- Immediate publication on acceptance

- Open access: articles freely available online

- High visibility within the field

- Retaining the copyright to your article

Submit your next manuscript at $\gg$ springeropen.com 